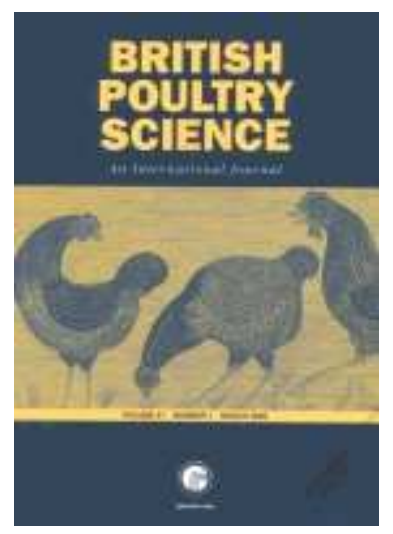

\title{
The use of conditioned place preference to determine broiler preferences for quantitative or qualitative dietary restriction
}

\begin{tabular}{|r|l|}
\hline Journal: & British Poultry Science \\
\hline Manuscript ID: & Draft \\
\hline Manuscript Type: & Original Manuscript \\
\hline Date Submitted by the & $\mathrm{n} / \mathrm{a}$ \\
\hline Complete List of Authors: & $\begin{array}{l}\text { Buckley, Louise; Harper Adams University College, Animals } \\
\text { Department } \\
\text { Sandilands, Victoria; Scottish Agricultural College, Animal Health } \\
\text { Hocking, Paul; Roslin Institute \& R(D)SVS } \\
\text { Tolkamp, Bert; Scottish Agricultural College, Animal Heath } \\
\text { D'Eath, Richard; Scottish Agricultural College, Sustainable Livestock } \\
\text { Systems }\end{array}$ \\
\hline Keywords: & Food restriction, Welfare, Behaviour, Breeders \\
\hline \multicolumn{2}{|c}{} \\
\hline
\end{tabular}

\section{SCHOLARONE ${ }^{m}$ Manuscripts}


1 TITLE PAGE

2 The use of conditioned place preference to determine broiler preferences for quantitative or

3 qualitative dietary restriction

4 Running title: Conditioned place preference and hunger broilers

5 Buckley, L. A. ${ }^{ \pm}$, Sandilands, V. ${ }^{1}$, Hocking, P. M. ${ }^{2}$, Tolkamp, B. J. ${ }^{1} \& D ’$ Eath, R. B. ${ }^{1}$

$6 \quad{ }^{1}$ Scottish Agricultural College, West Mains Road, Edinburgh, Midlothian EH9 3JG, UK.

$7 \quad{ }^{2}$ The Roslin Institute and Royal (Dick) School of Veterinary Studies, TheRoslin Institute Building,

8 Easter Bush, Midlothian, EH26 9RG, UK

$9 \pm$ Corresponding author:

10 L. A. Buckley,

11 Animals Department,

12 Harper Adams University College,

13 Newport,

14 Shropshire,

15 TF10 8NB

$16 \mathrm{UK}$

17 Tel: +44 (0) 1952815147

18 Fax: Not available

19 Email: 1buckley@ harper-adams.ac.uk 
1. $\underline{\text { Abstract }}$

1. Calcium propionate (CAP) may improve the welfare of feed restricted broiler breeders by improving their satiety when included within the feed ration. However, the evidence for this is mixed.

2. This study used a closed economy conditioned place preference (CPP) task and aimed to identify whether broilers (as a model for broiler breeders) preferred an environment associated with quantitative food restriction (QFR) or an environment associated with a diet qualityadjusted by the inclusion ofCAP. Birds taught to associate different environments with QFR and ad libitum (AL)access to feed were used to validate the methodology.

3. The two treatment groups were 1) QFR/AL $(\mathrm{n}=12)$ in which birds alternated every two days between QFR and ad libitum access to food, and 2) QFR/CAP $(\mathrm{n}=12)$ in which birds alternated every two days between QFR and QFR + calcium propionate (increased from 3 9\% over the study period). Birds were taught to associate one diet option with vertical stripes and the other with horizontal black and white stripes. Each bird was tested twice for a CPP (once per diet).

4. QFR/AL birds showeda significant preference for the pen associated with ad libitum access to feed, but onlywhen tested hungry (i.e. fed QFR on day of testing).QFR/CAP birds did not show a preference under either hunger state.

5. Reasons for the failure of QFR/CAP birdsto show a preference are unclear but could include a lack of preference or failure to learn the task.

6. The existence of state-dependent effects indicates that care is needed in the design of future CPP studies and that the effect of calcium propionate and level of hungeron ability to learn a CPP needs further investigation.

\section{Introduction}

51 Broiler breeders of fast growing strains of broilers (the most common commercial lines) are feed

52 restricted to ensure that the bird has a healthy rate of growth and maximal rates of fertility (Savoryet 
al 1993). This feed restriction is both severe, with birds fed as little as $25-45 \%$ of ad libitum intake

54 (dependent on whether comparisons are made between age or bodyweight-matched birds; Savoryet al 55 1993), and chronic, with birds being feed restricted to various degrees from about 1 week of age until 56 the end of their productive life (circa 18 months; based on manufacturer performance objectives, 57 Aviagen, 2007). The available behavioural and physiological evidence indicates that these birds 58 experience chronic hunger (Savoryet al 1993; Savory and Maros, 1993; Savory and Mann, 1999; 59 Hocking et al 1993, 1996, 2004; De Jong et al 2003). With around 6.3 million broiler breeders being 60 reared in 2010 alone in the UK (DEFRA, 2011) feed restriction is a major welfare issue within the 61 meat bird industry.

Quality adjusted diets that take longer to consume potentially improve feed restricted broiler 63 breeder welfare by increasing satiety and allowing more naturalistic foraging behaviour to occur (for a 64 review see D'Eathet al 2009). However, there is a need for further research to quantify this perceived 65 benefit by using methods that identify the relative affective state of the broiler when fed either a 66 quantitatively or qualitatively restricted diet. One potential dietary adjustment that might improve 67 levels of satiety is the addition ofpropionate-containing compounds such as calcium propionate 68 (CAP). Propionate has been linked to increased feelings of satiety in humans Experimentally, the 69 addition of CAPto broiler feed has been shown to reduce feed intake by up to $25 \%$ when fed to 70 immature (4 - 8 week old) broiler breeders at a 3\% inclusion rate (Kapkowskaet al 2005) although 71 this declines to about an $8 \%$ reduction in feed intake by 18 weeks of age. Sandilands et al (2006) 72 achieved a larger voluntary reduction in feed intake by increasing the inclusion rate from $5-10 \%$ 73 over the rearing period, although the bodyweight of these birds was still significantly greater than 74 birds reared using quantitative feed restriction to commercial levelsat 6 and 12, but not 18 weeks of 75 age.

76 However, the mechanism by which propionate achieves this reduction of food intake is unclear. It 77 is thought to act by delaying gastric emptying and / or by various post-absorption effects on 78 metabolism (Arora, et al2011; but see Darzi, et al 2011). One plausible hypothesis is that this results 79 in a sensation of satiety (a positive affective state) which birds find rewarding. Alternatively though, 80 birds may find eating or utilising food containing CAP unpleasant in some way. Darzi, et al 81 (2008)found that when propionate was administered orally in a palatable form to humans there was no 
suppression of appetite. Metabolic acidosis might be induced at high inclusion rates, but at the low

83 levels typically used this is not a problem (Pinchasov and Elmaliah, 1994). Oral lesions have been

84 observed in some studies (Tolkamp et al 2005; Bolton and Dewar, 1964) suggesting oral discomfort

85 as a mechanism but this is not always observed (Buckley et al, unpublished data). The fineness of 86 mash diets, which is exacerbated by the inclusion of CAP, have also been implicated in the aetiology

87 of oral lesions (Gentle, 1986; Tolkampet al 2005). Studies which bypass the gastrointestinal tract by

88 injection of propionic acid (the active ingredient) also achieve appetite suppression (Pinchasov and

89 Elmaliah, 1989). Previous work by Buckley et al (2011) found that diets containing 3\% calcium

90 propionate were less preferred compared with an otherwise identical basal diet by broilers in a two-

91 pan simultaneous choice test. However, this preference may be sensory-led and not reflective of the affective state of the bird post ingestion (i.e. does it increase satiety relative to quantitative dietary restriction?). To summarise, the effect of CAP on feed intake might be a consequence of increased made. placed within the distinctive environment to be conditioned. If the drug results in a positive affective state then the animal will prefer this environment over one it is placed into after an injection of saline (which has no effect on affective state). However, CPP has also been demonstrated to occur as a consequence of natural reinforcements including food (e.g. Spyrakiet al 1982; Papp, 1988; Papp et al

110 studies are in rodents, CPP have been demonstrated in avian species including quail (Mace et al 1997; 
111 Akins et al 2004) and chickens (Bronson et al 1996; Hughes et al 1997). Recent work by Dixon et al

112 (2011) suggested feed restricted broiler breeders can learn a CPP using aversive stimuli that they are

113 exposed to for several days in a closed economy environment. Y- or T-maze type choice tests in

114 which feed restricted broiler breeders have to choose between different quantities or qualities of food

115 that were associated with distinctive arms of the maze proved unsuccessful in previous research

116 (Buckley et al 2011a, 2011b). Thus, it is appropriate to investigate methods in which the animal is in

117 contact with the to-be-conditioned stimuli for longer (e.g. at least eight days, Dixon et al

118 2011)compared to the time spent in a Y-maze arm (which may be as little as 2 seconds in commercial

119 feed restricted broilers before they make a choice and exit the maze, Buckley et al 2010b). Also

120 potentially beneficial is that in CPP testing the animal is tested in extinction (i.e. with no food present

121 that is likely to elicit impulsive behaviour).These methods may be more successful at determining

122 broiler breeder preferences for quantitative or qualitative dietary restriction. Further, training and

123 testing the animal in a closed economy conditioned place preference apparatus may allow preferences

124 based on the whole experience of each diet 'system' to be identified. This isbecause the animal will be

125 in contact with the to-be-conditioned stimulus post-consumption of the diet. Thus, the animal should

126 express a preference based on its overall affective state (primarily how hungry or satiated the bird felt

127 post-diet consumption) on days during which it experiences quantitative (or qualitative) dietary 128 restriction.

129 The current study hypothesised that feed-restricted broilers would show a preference when given a 130 choice between environments associated with quantitative dietary restriction (QFR) or qualitative 131 dietary restriction (diet containing CAP) in a closed economy CPP task. It was expected that the 132 direction of this effect would indicate whether the broilers found a diet qualitatively-adjusted with the 133 addition of CAP more or less aversive than commercial levels of quantitative dietary restriction.To 134 validate the study methodology, a second group of birds was given a choice between environments 135 associated with ad libitum(AL) access to food or QFR. It was expected that the birds would show a 136 preference for the ad libitum feed access environment. Novelty(preference for pen not housed in on 137 the day of testing) was identified as a problem in previous work by Dixon et al (pers. comm). 138 Therefore, here both groups of birds were tested twice (once on a day when fed QFR and known to be 139 in a state of hunger and once on a day when fed the alternative diet option and in a state of satiety (ad 
libitum fed birds) or an unknown state (CAP-fed birds)). Thisenabledthe identification and of pennovelty related effects. This also enabled the identification of any state-dependent preferences. It was predicted that state dependent effects would not be present as it was expected that birds would always prefer the environment that they associated with feeling satiated over one that they associated with

144 feeling hungry.

\subsection{Subjects}

Twenty-four female Ross 308 broiler chicks were used from 28 day old birds. Broilers were used here as a more readily available model for parent stock. Prior to this study the birds had been group reared on a $14: 10 \mathrm{~h}$ light: dark schedule (day $1-28$ ) and spot-brooded (day $1: 31^{\circ} \mathrm{C}$, reduced gradually to $21^{\circ} \mathrm{C}$ on day 21 and maintained at this temperature thereafter). The birds were fed a commercial starter chick crumb (Farmgate, BOCM Pauls Ltd., Ipswich, Suffolk, UK)ad libitum from 1 - 14 days and, thereafter, feed restricted in line with the recommended daily feed requirements for broiler breeders (Aviagen, 2007). The mean (standard deviation) bodyweight of the birds on admittance to the study was $528.8 \mathrm{~g}( \pm 32.3 \mathrm{~g})$ which was $20 \%$ heavier than the target bodyweight for broiler breeders at 28 days $(440 \mathrm{~g})$. They had no previous experimental history.

A study timeline is provided to provide a brief overview of the experimental design and use of the experimental subjects (Table one).

\section{TABLE 1 SHOULD GO HERE}

\subsection{Treatment groups}

Birds were blocked according to weight, and then randomly allocated to one of two treatment groups on day 28. The treatment groups were: 1) QFR versus qualitative feed restriction (in which the food had calcium propionate added; QFR/CAP, $\mathrm{n}=12$ ), and 2) QFR versus Ad libitum feed (QFR/AL, $\mathrm{n}=12$ ). Each bird thus experienced two different diets, depending on treatment group. There were two phases to the experiment: 1) pre-CPP stage, and 2) CPP training and testing. The diet regime remained the same across both phases.

\subsection{Diet and feeding regime}

Irrespective of treatment, all birds were fed at 09:00h. Feed remaining at 17:00h was removed and weighed. Daily feed intake was recorded for each bird. All birds alternated every two days (from day 
$28-67$ (end of study)) between the two diet options assigned to their treatment group. Within each treatment group, half the birds received QFR on the first two days followed by the alternative diet option (CAP or AL) on the following two days, and alternated thereafter ( $\mathrm{n}=6$ per treatment). The other half of the birds received these diet options in the reverse order ( $n=6$ per treatment).

173 The basis of all the diets was a custom-made grower mash (Target Feeds, Whitchurch, Shropshire, 174 UK) suitable for broiler breeders from 28 days of age. The diet was formulated to contain $165 \mathrm{~g} / \mathrm{kg}$ 175 crude protein and $12.1 \mathrm{MJ}$ ME/kg feed. Birds in the treatment group QFR/AL received only this diet. 176 They alternated every second day between QFR and ad libitum access to this diet between 09:00h 177 17:00h. Birds in the treatment group QFR/CAP alternated between QFR and a diet that was 178 qualitatively restricted by the inclusion of calcium propionate (CAP). The CAP option was the same 179 quantity of diet as received under QFR plus the addition of calcium propionate (Propimpex ${ }^{\circledR}$ CA 180 powder, Impextraco, Germany) mixed into the ration. The quantity of calcium propionate was 181 increased over the duration of the study, from $30 \mathrm{~g}-90 \mathrm{~g} / \mathrm{kg}$ total feed $(3-9 \%)$. The inclusion rate 182 started at 3\% based on previous work by the authors (Buckley et al 2011a) which indicated that this 183 ration would be consumable within $8 \mathrm{~h}$. This was then increased to maximise time taken to consume 184 ration whilst at the same time aiming to ensure that all birds fed that ration on that day had consumed $185 \geq 95 \%$ of the total ration by $17: 00 \mathrm{~h}$. Thus, the calcium propionate level was increased to $4 \%$ on day 18636 (or day 38), $5 \%$ on day 41 (43), $6 \%$ on day $45(47), 7 \%$ on day $49(51), 8 \%$ on day $57(59), 9 \%$ on 187 day 60 (62) and remained at 9\% until the end of the study. The levels of CAP were increased based on 188 previous work by the authors (unpublished observations) and Sandilands et al (2005) who found that 189 it was necessary to increase the levels of calcium propionate included in the feed over time. This was 190 presumably necessary as birds either adjusted to its properties or increased in relative severity of feed 191 restriction. Birds were observed hourly between 09:00 - 17:00h and the hour by which the full ration 192 was consumed was noted. At the end of the day any ration remaining was weighed: if $\geq 95 \%$ of the 193 ration had been consumed the bird was considered to have consumed the full ration within $8 \mathrm{~h}$. The 194 QFR ration was always fully consumed by $8 \mathrm{~h}$; however, the CAP ration was not (see figure four). 195 During the pre-CPP phase (days 28 - 43), where the ration failed to be fully consumed by 17:00h it 196 was left in the birds' pen overnight to allow additional time to consume the ration. On these days all 197 birds remained individually housed overnight. During the CPP phase (days $44-67$ ), surplus food was 198 discarded at 17:00h for birds failing to meet the criterion. This applied to one bird on day 45 and three 
birds on day 51 with the mean daily quantity consumed (\% of total ration) for these birds on these days was: $47.8 \mathrm{~g}(90 \%)$ on day 45 and $48.6 \mathrm{~g}(90 \%)$ on day 51.

\subsection{Housing \& husbandry}

202 For the duration of the study, the birds were individually housed during the light hours in pens 203 containing wood shavings, a perch and a drinker allowing ad libitum access to water. Birds were pair204 housed overnight (exceptions outlined in the diet and feeding regime section).

205 The standard enclosure was a $0.95 \mathrm{~m}$ (width) $\times 1.05 \mathrm{~m}$ (length) $\times 0.8 \mathrm{~m}$ (high) solid-sided metal pen. 206 These pens were split down the middle with a wood divider creating two identical smaller pens 207 measuring $0.475 \mathrm{~m} \times 1.05 \mathrm{~m}$. Each divider had a removable solid door $(0.4 \mathrm{~m}$ high $\times 0.25 \mathrm{~m}$ long $)$ set 208 into the front bottom corner of the divider. The removable solid door was replaced with a removable 209 mesh door for the first 10 days to reduce the initial stress of social isolation in the birds. The front of 210 the pen comprised two sections. The top $0.4 \mathrm{~m}$ was a full-length mesh door that could be opened to 211 allow easy access to the pen. The bottom $0.40 \mathrm{~m}$ was a full length solid wooden divider. Set midway 212 along this divider was a hatchway $(0.25 \mathrm{~m} \times 0.25 \mathrm{~m})$ with a guillotine door. This hatchway lined up 213 with the central pen divider such that the divider bisected the guillotine door.

214 There were 12 of these divided pens in total. One bird was housed on each side of the divider (i.e. in 215 one of the 24 smaller pens).The feed bowls were placed at the front of the pen attached to a mesh grid. 216 The distance between the feed bowls and the floor was adjusted as periodically as the birds grew to 217 ensure ease of access but minimise spillage of feed.

218 The birds' pens werewithin a room that was maintained at $21^{\circ} \mathrm{C}$ throughout the study. The 219 photoperiod was gradually reduced from 14h / day (day 28) to 9h / day (day 33) to ensure the birds experienced a similar light period as commercially reared broiler breeder birds who are maintained on 8h light (it was slightly longer in our study to account for end of day experimental procedures (e.g. feed removal, etc). Thereafter, birds were given 9 hours light / day (09:00h $-18: 00 \mathrm{~h})$ with the exception of the 6days on which pre-existing side bias testing and CPP testing occurred (days 37, 38, $39,40,55$ and 67$)$. On these days the number of hours of lighting was extended until 21:00h to allow the end of day data collection to occur.

\subsection{Pre-CPP phase}

The purpose of the pre-CPP phase was to allow the birds to habituate to the test conditions (solitary housing), to adjust to the diet options on offer (to prevent dietary neophobia or initial sensory-led 
preferences affecting CPP formation) and to enable the identification of any birds with side-biases to

allow this to be controlled for.

\subsubsection{Housing protocol during pre-CPP phase}

The pre-CPP phase took place between days $28-43$. Birds were housed individually in the divided pens between 09:00h - 17:00h. At 17:00 the door in the central divider was removed allowing the birds housed on each side of the divider to move freely between the two pens. The two birds were allowed to interact until 18:00h before being returned to their pen(if any birds had failed to fully consume the feed ration) or 09:00h (if all birds had fully consumed the feed ration). All birds were housed individually overnight if any had not fully consumed the ration in order to maintain consistency between birds. This social interaction was instigated on ethical and welfare grounds and no data was collected during this interaction. In practice, there were nine days during the pre-CPP 240 phase in which it was necessary to house the birds individually overnight.Birds alternated daily 241 between the two pens they were housed in to habituate them to regular changes of environment whilst 242 preventing the association of the diet options with specific pens during the pre-CPP phase, since diets 243 alternated every two days throughout.

\subsubsection{Side bias testing during pre-CPP phase}

245 Each bird was tested 4 times for the presence of a pre-existing side bias. Side bias testing took place 246 between $17: 15 \mathrm{~h}-20: 15 \mathrm{~h}$ on days $37,38,39$ and 40 . Testing was balanced within bird with half the 247 tests taking place on days when the bird had been fed QFR and half the tests taking place on days 248 when the bird had been fed the alternative diet option (CAP or AL). Half the tests took place on the $1^{\text {st }}$ 249 day post switch to the QFR (or alternative diet option) and the remaining half took place one $2^{\text {nd }}$ day 250 (i.e. the day before switching to the other diet option). The side-bias testing procedure was as follows: 251 each bird was removed from its pen $15-20$ minutes before it was tested for a side bias and placed in 252 a holding pen. The bird occupying the adjacent pen was removed and placed in another holding pen 253 just before testing of the first bird commenced. Both pens (each side of the divider)were cleaned out 254 and fresh wood shavings added. The feed bowl and associated attachments were removed. The door 255 in the wooden divider was removed. The bird was then placed in a box $(0.25 \mathrm{~m}(\mathrm{w}) \times 0.30 \mathrm{~m}(\mathrm{l}) \mathrm{x}$ $2560.35 \mathrm{~m}(\mathrm{~h}))$ that was lined up with the guillotine door. After 30 seconds the guillotine door was raised 257 and the bird was allowed to enter either pen and allowed to move freely between both pens for 20 minutes. The bird was then removed, returned to the holding pen and the other bird tested. Once both 
birds occupying adjacent pens had been tested both birds were returned to the pens. First penentered was recorded. Each bird was observed continuously and each time the bird changed pens this was recorded in seconds using a stopwatch. A bird was considered to have changed pens when both feet had entered the neighbouring pen.

The criterion for a bird being considered to have a pre-existing side bias was more than $60 \%$ spent on a particular side out of the total amount of time the bird was observed for ( 80 minutes). This $60 \%$ threshold was based on the work of Dixon et al (pers. comm.). Within the QFR/AL group 4 birds had a right sided bias and 5 birds had a left sided bias. Within the QFR/CAP group 6 birds had a rightsided bias and no birds had a left-sided bias.

\subsection{CPP phase}

This phase comprised CPP training and both tests for the existence of a CPP.

\subsubsection{Conditioned place preference apparatus}

The CPP apparatus was the same divided pens as used for the pre-CPP phase as described above butcoveredfrom floor level to a height of $0.7 \mathrm{~m}$ on the side and back walls of the pen with sheets of varnished and laminated paper. Each adjacent pen (i.e. separated from each other by the divider) had paper sheets with one of two patterns. In one pen the pattern was vertical black and white stripes( $33 \mathrm{~mm}$ wide stripes), while in the other pen it was horizontal black and white stripes $(16 \mathrm{~mm}$ wide stripes; Figure 1). This was balanced such that half the 'vertical-striped' pens were on the right side of the divider and the 'horizontal-striped' pens on the left side and vice versa. Both pens were designed to ensure an equal coverage of black and white to control for brightness.

\section{FIGURE 1 GOES HERE: DIAGRAM OF CPP APPARATUS}

\subsubsection{CPP training and housing protocol}

On day 44, CPP training began and lasted until day 67 (end of the study). Each bird lived in one of the distinctive pens on days when it received QFR and the other distinctive pen on days when it received AL (QFR/AL treatment group) or CAP (QFR/CAP treatment group). The aim was to allow the birds to associate the different pens with the state of hunger that they experienced within them. Within treatment, half the birds $(n=6)$ experienced QFR in the vertically striped pens (for three birds this was the right sided pen and for three birds this was the left-sided pen) and half $(n=6)$ experienced QFR on the horizontally striped pens (also balanced for pen side). To control for pre-existing side biases birds that demonstrated a pre-existing side bias were approximately equally distributed such 
that, within each treatment group, half the birds received QFR on their preferred side and half received QFR on their least preferred side.

291 Birds lived in the CPP apparatus continuously. Between 09:00h - 17:00h birds were housed individually. Overnight, they were pair-housed with another bird. The conspecific they were housed with remained the same throughout this phase. Birds were paired according to treatment group and pen pattern experienced that day (i.e. a bird that had been housed in a vertical striped pen was housed overnight with another bird that had experienced vertical stripes that day and both birds were from the same treatment group). On days when birds were switched between environments they were switched at 09:00h before being fed.

\subsubsection{CPP testing}

Each bird was tested for a CPP after 12 days training ( 6 days per diet: environment pairing; tested on day 55) and 24 days training (12 days per diet: environment pairing; tested on day 67). The CPP testing protocol was identical to theprotocol for side bias determination.

\subsection{Statistical analysis}

All statistical analyses were undertaken using Genstat $\left(13^{\text {th }}\right.$ Edition, VSN International, Ltd., Hemel Hempstead, UK). The Shapiro-Wilks test was used to evaluate the distribution of proportion data which was normal. Therefore, untransformed data and a repeated measures REML was used to investigate any differences between treatments, effect of state at the time of testing and interactions between these. Number of pen changes was normalised using the log-e transformation prior to REML analysis. For all analyses, subject was the bird ID. The relevant time point was test number and these were equally spaced and identical between subjects. The fixed effects were: treatment, diet option fed 311 interest tested were: proportion of time spent on the non-QFR side; proportion of time spent in the 312 'novel' pen; proportion of time spent in the right pen. Differences from 0.5 were evaluated using the 313 One-sample T-test. Where confidence intervals are reported these are at the 95\% significance level.

314 First pen entered data was tested using a GLMM with a logit-transformed binomial distribution. The 315 variables of interest included: which pen was entered (associated with QFR or alternative diet; right or 316 left sided pen; novel pen or pen bird spent the day of testing in). The fixed effects examined included: 317 treatment, state at time of testing; pattern associated with QFR and all interactions between these. The random effect was bird ID. Differences from 0.5 were calculated by chi-square (1 d.f.) using a test 
statistic generated by the following formula: $\chi^{2}=(\text { predicted mean / S.E. of the predicted mean })^{2}$.

Predicted means were generated by GLMM.

\subsection{Ethical considerations}

This study was carried out under Home Office license and was approved by both the Scottish Agricultural College's and Roslin Institute's Animal Ethics Committees. Pen sizes exceeded the

342 Over the duration of training and testing the level of feed restriction of QFR/CAP birds was 22 -

4. Results

\subsection{Growth curves}

QFR/CAP birds grew at a similar rate to the commercial target (Figure 2), while QFR birds grew at a faster rate. This was to be expected as QFR/CAP birds were fed a similar quantity of basal diet as birds fed to commercial levels of feed restriction, while QFR/AL birds consumed considerably more feed on days when they were fed an ad libitum ration (Figure 3). The average consumption ( \pm standard deviation) on ad libitum days was $58.3 \mathrm{~g}( \pm 5.2 \mathrm{~g})($ day 29$)-204.9 \mathrm{~g}( \pm 10.9 \mathrm{~g})$ (day 67$)$.

\section{FIGURE 2 GOES HERE: DIAGRAM OF GROWTH CURVES} $24 \%$ (compared with birds of the same age) or 43 - $44 \%$ (compared to birds of similar bodyweight) of the QFR/AL birds ad libitum intake (range established from the first and last days of CPP training and resting, i.e. days 44 and 67 and based on the difference between the QFR ration for the QFR/CAP birds and the estimated daily intake of ad libitum fed broilers (Aviagen, 2007) for birds of a similar 
FIGURE 3 GOES HERE: DIAGRAM OF FEED INTAKE

4.2. Time taken to consume QFR or CAP ration by $Q F R / C A P$ birds

As expected the CAP ration always took longer to consume than the QFR ration (Figure 3). However,

there was considerable variation between birds in relation to the time taken to consume the CAP

ration. The inter-day median time (with inter-quartile range shown) taken to consume the CAP ration across the period of CPP training and testing (day $44-67)$ was $6.2(5.7-7.2)$ hours. However, intraday there was considerable more variation apparent between birds (Figure 4).

FIGURE 4 GOES HERE: TIME TAKEN TO CONSUME EITHER THE CAP OR THE QFR RATION

4.3. Proportion of time spent in each pen

362 The main variable of interest was the proportion of time the birds spent in either the pen associated with QFR or the pen associated with ad libitum access to feed (QFR/AL treatment group) or CAP (QFR/CAP treatment group). Here an effect of state at the time of testing $\left(\mathrm{F}_{1,16}=5.43, \mathrm{P}=0.033\right)$ was observed. Post-hoc testing from 0.5 (no preference) indicated that only hungry (i.e. fed QFR on the day of testing) QFR/AL birds showed a significant preference $\left(\mathrm{T}_{11}=3.27, \mathrm{P}=0.007\right)$. This preference was for the pen associated with ad libitum access to feed (mean preference: 0.653; C.I. $0.550-0.757$ ) (Figure 5). Ten out of 12 QFR/AL birds spent more time (shown as a proportion of total time tested) on the non-QFR pen when tested under conditions of feed restriction. The QFR/AL group mean of 0.45 (C.I. $0.29-0.60$ ) did not differ significantly from 0.5 on days when QFR/AL birds were satiated $\left(\mathrm{T}_{11}=0.75, \mathrm{P}=0.467\right)$. No significant pen preferences were observed for QFR/CAP birds either when tested on QFR days $\left(\mathrm{T}_{11}=1.19, \mathrm{P}=0.259\right)$ or on CAP days $\left(\mathrm{T}_{11}=0.52, \mathrm{P}=0.611\right)$. The QFR/CAP group mean was 0.57 (C.I. $0.44-0.69$ ) on QFR days and 0.52 (C.I. $0.42-0.62$ ) on CAP days. 
$\mathrm{P}=0.946)$ in terms of proportion of time spent in each pen. Importantly, there was no effect of pennovelty with QFR/CAP birds showing no preference for either for or against the pen they had spent the last two days living inregardless of diet option fed on the day of testing (Tested on CAP day: mean: 0.48; C.I. $0.38-0.58 ; \mathrm{T}_{11}=-0.34, \mathrm{P}=0.739$; Tested on QFR day: mean 0.57; C.I. $0.44-0.69$; $\mathrm{T}_{11}=1.19, \mathrm{P}=0.259$ ). QFR/AL birds tested under conditions of hunger (i.e. fed QFR on the day of testing) showed a significant preference for the novel pen. In this instance this corresponded with the preference for the pen associated with ad libitum access to feed, suggesting that the treatment effect was responsible, rather than a preference for novelty under only these circumstances. They did not show a preference when tested on days when fed ad libitum (mean: 0.45; C.I. $0.40-0.7 ; \mathrm{T}_{11}=0.75$, P $=0.467)$.

\subsection{First pen entered}

First pen entered did not reveal any significant preferences for either distinct environment. There was no effect of treatment $\left(\mathrm{F}_{1,22}=0, \mathrm{P}=1\right)$, state at time of testing $\left(\mathrm{F}_{1,42}=0.33, \mathrm{P}=0.566\right)$ or pattern $\left(F_{1,21.9}=2.75, P=0.111\right)$. Neither group entered the pen associated with novelty $\left(\mathrm{QFR} / \mathrm{AL}: \chi^{2}=0.24\right.$, d.f. $=1, \mathrm{P}>0.05 ; \mathrm{QFR} / \mathrm{CAP}: \chi^{2}=0.16$, d.f. $\left.=1 ; \mathrm{p}>0.05\right)$ or the pen associated with the non-QFR diet option (QFR/AL: $\chi^{2}=0.10, \mathrm{P}>0.5$; QFR/CAP: $\chi^{2}=0.10, \mathrm{P}>0.05$ ) significantly more or less than 0.5 . Furthermore, a side bias was no-longer evident in either treatment group (QFR/AL: $\chi^{2}=0.10, \mathrm{P}>0.05$; QFR/CAP: $\left.\chi^{2}=2.60, \mathrm{P}>0.05\right)$.

\subsection{Number of pen changes}

400 The median (inter-quartile range) number of changes between pens during tests was $14(9-19.5)$ for 401 the QFR/AL treatment group and $18(11-25.5)$ for the QFR/CAP treatment group which was not statistically significant $\left(\mathrm{F}_{1,22}=2.47, \mathrm{P}=0.13\right)$. There was also no effect of diet option fed on day of testing $\left(\mathrm{F}_{1,22}=0.2, \mathrm{P}=0.661\right)$ and no interaction between treatment and diet option fed on day of testing $\left(\mathrm{F}_{1,22}=0.07, \mathrm{P}=0.793\right)$.

\section{Discussion}

406 The key significant findings from this study were that the QFR/AL birds expressed a preference for 407 the pen associated with ad libitum feeding but only under conditions of deprivation (hunger) and the 
birds in the QFR/CAP group failed to demonstrate a preference for the environment associated with either diet option.

\subsection{The QFR/AL birds' pen preferences}

411 The finding that feed restricted broilers could learn a food-rewarded CPP under certain 412 circumstances (the control group, i.e. QFR vs. AL feeding) but express it only when acutely feed 413 restricted was unexpected. The failure of the QFR/CAP birds to show evidence of attraction to the 414 novel pen suggested that the QFR/AL birds were not attracted to a pen due to its relative 'novelty'.

415 Further, the lack of difference in pen changes between the two groups of birds or interaction with state 416 at time of testing provided a crude indicator that the QFR/AL birds when tested under conditions of 417 hunger had not simply picked a pen to forage in(anecdotally, the predominant activity) and then failed 418 to move. Rather, theyrepeatedly returned to their favoured side. Thus, it seems that a state-dependent 419 preference was being observed. This provided an interesting additional or alternative explanation for 420 the birds' preference expression. It had been assumed that the birds would pick the pen associated 421 with feeling more satiated because this is a positive affective state and birds would prefer to spend 422 their time in a pen they associate with feeling 'good' (satiated) rather than in a pen they associate with 423 feeling 'bad' (hungry). This is the basis for most CPP tests in pharmacological research (Tzschentke 424 1998; Bardo and Bevins, 2000). However, Spiteriet al (2000) found that morphine-conditioned rats 425 spent less time active and more time in close association with the conditioned stimulus. By 426 comparison, food-conditioned rats were more active and showed more exploratory behaviour. They 427 concluded that rats given morphine had associated the environment with the post-affective state 428 induced by morphine. By contrast, rats rewarded with food had learnt that the food-rewarded environment was a good place to find food which stimulated appetitive, food-seeking behaviour. This 430 suggests that the QFR/AL birds in our study, when tested on days when hungry, perhaps selected the 431 pen associated with ad libitum food supply not because they associated that environment with a more 432 positive state but because they anticipated that they would be more likely to obtain food within this pen.

434 Few food rewarded-CPP studies have used a within-subject comparison between state of 435 deprivation (e.g. hungry versus not hungry) to assess hunger-state-dependent preferences. Perks and 436 Clifton (1997) trained food deprived (to a bodyweight no less than 85\% of ad libitum intake), water437 satiated rats to associate one environment with sweetened mash diet and another environment with 
sweetened water. Both rats were then tested under two different motivational states: thirst and hunger.

They found a state-dependent preference: the rats preferred the pen associated with water when thirsty and vice versa. This indicated that therats associated each distinct environment with resources of

441 potential future value rather than post-consummatory affective state during training (although this

442 latter association may also have occurred). Otherwise, the rats would have shown a preference for the

443 mash-associated pen as they encountered this in a state of deprivation during training so its

444 motivational value at the time of learning should have been higher than the sugar water. Further, the

445 authors demonstrated that devaluing the sugar water post training of the CPP by pairing it with

446 lithium chloride (in the home pen) reduces the strength of CPP expressed.

447 Where between-subject studies have been performed they have indicated that the pre-fed animal 448 demonstrates either no CPP (Figlewiczet al 2001) or an attenuated CPP (Bechara and van der Kooy,

449 1992; Leporeet al 1995). Although some studies have found a food-rewarded CPP in non-deprived 450 subjects (Papp, 1988; Papp, 1989; Papp et al 1991; Bechara and van der Kooy, 1992; Muscat et al 451 1992; Willner, et al, 1994; Leporeet al 1995) the studies by Papp (1988, 1989, 1991), Muscat (1992) 452 and Willner (1994)all adopted a methodology that included feed restriction throughout training. The 453 rats are described as pre-fed before training but limited detail is available so it is difficult to determine 454 how satiated the rats would have been before testing for CPP. It seems unlikely that the rats would 455 have fully compensated for chronic feed restriction during training during the small interval between 456 cessation of training and the CPP test (at most 24 hours). By contrast, our methodology in which 457 broilers alternated every two days between feed restriction and ad libitum feed regimes probably 458 allowed the birds to compensate to a degree as broilers can increase feed intake to near ad libitum 459 levels on skip-a-day regimes (Dunnington, 1987). Thus our QFR/AL birds were expected to be 460 satiated on days when given ad libitum access to feed prior to CPP testing.

461 Most food-rewarded CPP tasks train and test the animals under the same condition (Feed restriction: 462 Guyon, et al 1993; Popik and Danysz, 1997; Chaperon, et al 1998; Spiteriet al 2000; Figlewiczet al 463 2001; Yonghuiet al 2006; Zombecket al 2008; Koizumi, et al 2009; Ad libitum access: Imaizumiet al 464 2000, 2001; Jaroszet al 2006; Dickson et al 2010; Matsumura et al 2010); therefore, it is not possible 465 to clearly disentangle the effects of training (state-dependent learning) from testing (state-dependent 466 preference). However, state-dependent preferences have been observed in food- and sucrose water- 
opioid receptor antagonist) (Delamater et al 2000) abolish food and sucrose conditioned CPPs respectively when injected before testing rats for CPP presence. In contrast, the dopamine receptor agonist, MK-801, both increases feed intake and potentiates expression of food-rewarded CPPs when administered pre-test (Yonghuiet al 2006). Finally, Larson (2006) found a sucrose-water CPP was only expressed when rats were water deprived prior to testing. These studies indicate that state at time of testing can affect the expression of food (or water) rewarded CPP. The current study supports these 474 studies and indicates that the state of the animal during testing should be considered when designing 475 CPP studies to determine feed preferences in feed restricted broilers.

476 However, environmental preferences have been observed in animals pre-fed prior to testing for a 477 food-rewarded CPP. Papp (1988), Papp et al (1990) and Spyrakiet al (1982) all trained under 478 deprivation and fed prior to testing and found the rats demonstrated a CPP (but the effects of prior 479 deprivation cannot be discounted as a motivator in these methodologies). No studies were found that 480 trained under ad libitum conditions and tested under conditions of feed restriction (i.e. tested during a 481 state of deprivation). Imaizumiet al (2000, 2001), Jaroszet al (2006), Matsumura et al (2010) and 482 Dickson et al (2010) used rats fed ad libitum on chow outside the training situation. However, they 483 trained a CPP in which the rewarding environment was associated with a higher value 'treat' food not 484 available outside of the test situation. For example, corn oil (Imaizumiet al 2000, 2001) high sugar or 485 high fat foods (Jaroszet al 2006), chocolate drops(Dickson et al 2010) or pre-training gastric infusions 486 of glucose or corn oil paired with low nutritive foods within the apparatus (Matsumura et al 2010).By 487 contrast, the less rewarding environment was associated with rat chow (except Imaizumiet al 2000, 488 2001, who used plain water). However, it is reasonable to assume any CPP that develops under these conditions develops as a consequence of a hedonic state induced by something other than the reduction of hunger. Thus, attainment of satiety (or, at least, reduction in hunger) is not a necessary condition of food - rewarded CPP learning. This has implications for the use of CPP to determine 492 affective state in quantitative or qualitatively-restricted broilers both in how the test should be used and what should be inferred from the demonstration of a food-rewarded CPP.

495 The state-dependent preference observed in the QFR/AL group does not explain why the birds in 496 the QFR/CAP group did not express a preference for one of the distinctive environments. This could 497 have resulted from a failure to express a preference despite having learnt the relevant associations 
with environment or a failure to learn the task (and thus an inability to express any preference). These shall be discussed in turn.

\subsubsection{Learnt the task but no preference exhibited?}

One possibility for the failure to exhibit a preference is that the birds genuinely did not have a preference for either environment, perhaps because both distinct environments provided similar opportunities for the reduction of hunger. Alternatively, whilst differing across various dimensions (e.g. post-ingestion effects, sensory-led effects) the net effect in terms of affective state for the bird may have been perceived as similar between environments (e.g. the QFR environment may have offered a more palatable diet option than the CAP environment but resulted in higher levels of hunger than that experienced in the CAP environment). This study was not designed to investigate foraging decisions in hungry broilers. However, the finding that the QFR/AL birds expressed a preference for the pen associated with ad libitum feed access suggested that the birds selected the pen based on whether it was previously a good environment to forage in. Therefore, if a broiler's foraging behaviour is sensitive to time and it is able to recognise when food is likely to be available within an environment then our study design contained an inherent weakness. Namely, birds were tested during a period in which they had never received, or had access to, food. Most food-rewarded CPP studies are not closed economy and are likely to conduct their tests during a similar time of day to which the training took place. Therefore, the animal would enter the CPP apparatus expecting to find food within the chamber(s) that it had associated with food.

Both previous research by the authors and anecdotal observations in the current study suggested that the CAP option was aversive. Tolkampet al (2005) noted oral lesions (presumably associated with pain)when feed restricted broiler breeders were fed a mash diet which included $90 \mathrm{~g}$ calcium propionate/ kg total feed. In the current study no gastrointestinal lesions were noted either during the study or at post-mortem. However, it was informally observed that some birds tried to escape the pen immediately upon being given their CAP ration (but never their QFR ration). This suggested that, whilst CAP was not associated with lesions (and the associated discomfort) it was not as favourably received by the birds as the QFR ration. Thus, it was unexpected that a preference would not be observed during the formal testing and suggested that the diet option: distinct environment association had not been learnt.

\subsubsection{A failure to learn the task?}


528 A failure to learn the task appears counter intuitive given that QFR/AL birds did learn the task.

529 However, several points can be made in favour of this interpretation. Firstly, QFR/AL birds expressed

530 this state-dependent preference when hungry. There was at least one diet condition under which the

531 QFR/CAP birds would have been hungry (QFR days). Therefore, there was at least one day during

532 which the birds would have been in a state in which 'preference expression' (assuming one existed)

533 could be anticipated. If birds were hungry on only one day or, at least less hungry on one day this

534 would suggest that one diet was more satiating (and, presumably, more rewarding) and should have

535 been preferred. Despite this, a preference was not expressed.

536 Secondly, ifthe effects of CAP on bird wellbeing (positive or negative) are not due to increased

537 satiety, then the birds were trained and tested while fed a quantity of feed similar to commercial levels

538 of feed restriction.Quantitative feed restriction is associated with behavioural and physiological

539 indicators of stress in broiler breeders (e.g. Hocking et al 1993, 1996; de Jong et al 2002, 2003). Feed

540 restriction is also associated with physiological changes such expression of, and levels of, certain

541 nutritional-status-related compounds that may affect cognition (e.g. ghrelin, Dianoet al 2006;

542 synapsin proteins, Deng et al 2009). Buckley et al (2011b) found feed restriction resulted in poorer

543 performance on a food quantity discrimination task with all birds fed to commercial levels of feed

544 restriction failing to learn a food quantity discrimination task. Although most animals taught a food-

545 rewarded conditioned place preference task are feed restricted, the level of restriction is less severe

546 than the birds experienced (assuming that CAP had no or minimal satiating effects). Where reported,

547 most studies restricted their animals (rats or mice) to somewhere within the range of $80-90 \%$ of $a d$

548 libitum fed bodyweight (85 - 90\%, Leporeet al 1995; 85\%, Delamater et al 2000; 90\%, Stuber et al,

$5492002 ; 80-85 \%$, Yonghuiet al 2006) or circa 50\% of expected ad libitum intake (Figlewiczet al 2001).

550 This was less severe than the birds in this study. Further, for these animals, feed restriction began

551 shortly before the study commenced. By contrast, the birds in the current study had experienced feed

552 restriction from 14 days of age.Therefore, the birds in this study were considerably more feed

553 restricted than in most other studies and this may have negatively affected learning.

554 Thirdly, high doses of propionate (sufficient to induce acidaemia) have been associated with later

555 learning impairments in rats (Brusque, et al 1999; Pettenuzzo, et al 2002; Shultz, et al 2009;

556 MacFabe, et al 2011). However, methodological differences limit the inferences that can be drawn.

557 For example, those studies administered propionate subcutaneously (Brusque et al, 1999; Pettenuzzo, 
et al 2002) or via intracerebroventricular injection (Schultz, et al 2009; MacFabe, et al 2011) whereas the birds in our study received CAP orally and could choose how much they ingested and over what timeframe. Despite this, it cannot be discounted as a possible factor affecting the ability of the QFR/CAP birds to learn the CPP task.

562 Finally, extraneous stressors may have synergistically interacted with dietary stressors to prevent learning in the QFR/CAP birds. Chickens are a social species so social isolation can be expected to be

564 stressful. Chronic social isolation negatively affected morphine or heroin rewarded CPP formation in 565 rats (Kiyatkin and Belyi, 1991; Courdereau, et al 1997).The birds in the current study were 566 individually housed during the day during the training and testing periods.This methodology was 567 adopted due to concerns that testing the birds in pairs contributed to the lack of preferences exhibited 568 in the Dixon et al (pers. com) study. However, the long latency to consume the QFR ration by 4 week old QFR/CAP birds (data for QFR/AL birds was not recorded) immediately post-separation was 570 atypical and unanticipated (they were consuming the daily ration in less than 40 minutes (unrecorded 571 data) in the couple of days immediately preceding separation). The most reasonable explanation is 572 this was primarily the effect of separation as increased vocalisation and attempts to access the other 573 bird were evident. Further, the switch between the QFR ration and the CAP ration may have been 574 experienced both as an uncontrollable and unpredictable environment condition (key components of 575 many stressors, Wiepkema and Koolhaas, 1993) which would act as additional stressor. Exposure to 576 chronic low level stressors has been demonstrated to abolish or attenuate either the learning and / or expression of a food - rewarded CPP task (Papp et al 1991; Cheetaet al 1994; Willneret al 1994).

578 This may be particularly relevant in studies that use a closed economy design as the impact of environmental stressors can be protracted during CPP training.

\subsection{Other methodological issues}

584 observations) and Dixon (pers. comm.) indicate that the birds utilise these shavings extensively for

585 foraging. It is inevitable that spilt food will be discovered reinforcing this behaviour. Further, in other 586 experiments by the authors, birds consume wood shavings with considerable crop fill noted for some 587 birds both whilst alive (author's own observations) and during post-mortem (Hocking, pers. comm.). 
588

589

590

591

592

593

594

595

596

597

598

599

600

601

602

603

604

605

606

607

608

609

610

611

612

613

614

615

616

617
Thus, shavings may have non-nutritive satiety-promotingproperties (assuming that a full crop promotes satiety). In addition, shavings allow some natural behaviour to occur, occasionally yieldinga nutritive morsel and distracting the birds' attention from the cues signifying the diet option to be found within this environment. Regardless of the underlying potential value or impact of providing shavings it is suggested that it was an error to provide (or at least not control for) shavings during testing. De Jong et al (2008) investigated CPP formation in pigs and found that pigs could form a CPP to an environment containing straw to forage in suggesting this was rewarding to pigs. Despite this, the performance of the QFR/AL birds indicates that, even with shavings provided during testing birds are able to demonstrate a CPP. This does not, however, account for the expected differential and / or relative value of shavings under the various feed options the birds encountered.

\section{Conclusions and further research}

It is concluded that there is some evidence that feed restricted broilers can learn a food quantity associated CPP task. However, the presence of state-dependent preference expression means that it is essential to take this into consideration when designing such studies to maximise the chances of identifying a preference where one exists. Further, there was no evidence that CAP improves the welfare of feed restricted birds. Whilst a CPP was not observed, informal observations indicated that the birds did not like the CAP diet. Therefore, the more plausible interpretation is the birds failed to learn the task.However, this has not been shown by this current study and a genuine lack of preference cannot be discounted. Thus, further research should investigate the effect of both plane of hunger and calcium propionate on ability to learn a CPP task before adopting this technique more widely as a tool for the assessment of the welfare benefits of qualitatively-restricted diets.

\section{Acknowledgements}

The Universities Federation for Animal Welfare (UFAW) is gratefully acknowledged for funding a research training scholarship for the primary author. SAC is supported by the Scottish Government. The Roslin Institute is supported by the BBRSC.Laura Dixon is also thanked for her useful support and advice on the use of conditioned place preference methodologies.

8. References

AKINS, C. K., LEVENS, N., PRATHER, R., COOPER, B., FRITZ, T. (2004) Dosedependent cocaine place conditioning and D1 dopamine antagonist effects in male japanese quail. Physiology \&Behavior, 82: $309-315$. 
618 ARORA, T., SHARMA, R. \& FROST, G. (2011) Propionate: anti-obesity and satiety

619 enhancing factor?Appetite, 56: $511-515$.

620 AVIAGEN (2007) Ross 308: Parent stock management manual. Aviagen Ltd.,

621 Midlothian, UK. Available on line:

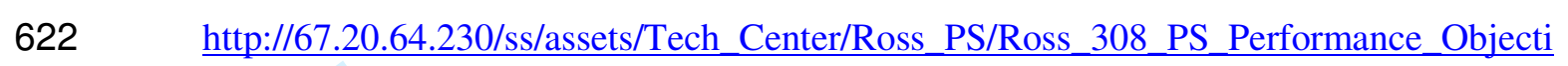

$623 \quad$ ves.pdf (accessed: 19/10/2010)

624 BARDO, M. T. \& BEVINS, R. A. (2000) Conditioned place preference: what does it 625 add to our preclinical understanding of drug reward? Psychopharmacology, 153: 31 62643.

627 BECHARA, A. \& VAN DER KOOY, D. (1992) A single brain stem substrate mediates 628 the motivational effects of both opiates and food in non-deprived rats but not in deprived 629 rats. Behavioral Neuroscience, 106: $351-363$.

630 BOLTON, W. \& DEWAR, W. A. (1964) The digestibility of aectic, propionic and 631 butyric acids by the fowl. British Poultry Science, 6: $103-105$.

632 BRONSON, M. E., WAGES, T. D., BEDDINGFIELD, T., HORNER, J. M., WILLIS, 633 L. L. \& SCOTT, JR., J. L. (1996) Morphine, MDMA, MDA, and Nexus produce a 634 conditioned place preference in newly hatched chickens. Experimental and Clinical 635 Psychopharmacology, 4: $354-362$.

636 BRUSQUE, A. M., MELLO, C. F., BUCANAN, D. N., TERRACCIANO, S. T., 637 ROCHA, M. P., VARGAS, C. R., WANNACHER, C. M. D. \& WAJNER, M. (1999) 638 Effect of chemically induced propionic acidaemia on neurobehavioral development of 639 rats. Pharmacology Biochemistry and Behavior, 64: 529 - 534. 
BUCKLEY, L. A., SANDILANDS, V., TOLKAMP, B. J. \& D’EATH, R. B., (2011a)

Quantifying hungry broiler breeder dietary preferences using a closed economy T-maze task. Applied Animal Behaviour Science, 133: 216 - 227. HOCKING, P. \& D'EATH, R. B. (2011b) Too hungry to learn? Hungry broiler breeders fail to learn a T-maze food quantity discrimination task. Animal Welfare, 20: TBC - in print in October 2011. of central cannabinoid $\left(\mathrm{CB}_{1}\right)$ receptors in the establishment of place conditioning in rats. Psychopharmacology, 135: 324 - 332. stress-induced anhedonia by mianserin and its (+)-enantiomer.Psychopharmacology, 116: $523-528$.

COURDEREAU, J. P., DEGRAY, M., MONIER, C., BOURRE, J. M. \& FRANCES, H. (1997) Isolation impairs place preference conditioning to morphine but not aversive learning in mice. Psychopharmacology, 130: 117 - 123.

657 propionate-rich sourdough bread on appetite and metabolic response. Proceedings of the $658 \quad$ Nutrition Society, 67(OCE8): E317.

659 DARZI, J., FROST, G. S. \& ROBERTSON, D. (2011) Do SCFA have a role in appetite 660 regulation? Proceedings of the Nutrition Society, 70: $119-128$. 
DEFRA (2011) Poultry and poultry meat statistics.A National Statistics Publication,

665 Department for Environment, Food and Rural Affairs, York, UK. Available from:

666 http://www.defra.gov.uk/evidence/statistics/foodfarm/food/poultry/index.htm (accessed:

$667 \quad 01 / 05 / 2011)$

668 DE JONGE, F. H., TILLY, S. L., BAARS, A. M. \& SPRUIJT (2008) on the rewarding

669 nature of appetitive feeding behaviour in pigs (Sus scrofa): do domesticated pigs

$670 \quad$ contrafreeload? Applied Animal Behaviour Science, 114: 350 - 372.

671 DELAMATER, A. R., SCLAFANI, A. \& BODNAR, R. J. (2000) Pharmacology of

672 sucrose-reinforced place preference conditioning: effects of naltrexone. Pharmacology

673 Biochemistry and behaviour, 65: $697-704$.

674 DE JONG, I. C., VAN VOORST, A. S. \& BLOKHUIS, H. J. (2003) Parameters for

675 quantification of hunger in broiler breeders. Physiology \&Behavior, 78: 773 - 783

676 DE JONG, I. C., VAN VOORST, S., EHLHARDT, D.A. \& BLOKHUIS, H. J. (2002)

677 Effects of restricted feeding on physiological stress parameters in growing broiler

678 breeders.British Poultry Science, 43: $157-168$.

679 DENG, L., WU, Z. N. \& HAN, P. Z. (2009) Effects of different levels of food restriction 680 on passive avoidance and the expression of synapsin 1 in young mice. International $681 \quad$ Journal of Neuroscience, 119: $291-304$.

682 DIANO, S., FARR, S. A., BENOIT, S. C., MCNAY, E. C., DA SILVA, I., HORVATH, 683 B., GASKIN, F. S., NONAKA, N., JAEGAR, L. B., BANKS, W. A., MORLEY, J. E., 684 PINTO, S., SHERWIN, R. S., XU, L., YAMADA, K. A., SLEEMAN, M. W., 685 TSCHOP, M. H. \& HORVATH, T. L. (2006) Ghrelin controls hippocampal spine $686 \quad$ synapsedensity and memory performance. Natural Neuroscience 9: 381-388. 
DICKSON, S. L., HRABOVSZKY, E., HANSSON, C., JERLHAG, E., ALVAREZCRESPO, M., SKIBICKA, K. P., MOLNAR, C. S., LIPOSITS, Z., ENGEL, J. A. \& EGECIOGLU, E. (2010) Blockade of central nicotine acetylcholine receptor signalling attenuate ghrelin-induced food intake in rodents. Neuroscience, 171: $1180-1186$.

DUNNINGTON, E. A., NIR, I., CHERRY, J. A., JONES, D. E., \& SIEGEL, P. B. (1987) Growth-associated traits in parental and F1 populations of chickens under different feeding programs. 3. Eating behaviour and body temperature. Poultry Science, 66: $23-31$.

FIGLEWICZ, D. P., HIGGINS, M. S., NG-EVANS, S. B. \& HAVEL, P. J. (2001) Leptin reverses sucrose-conditioned place preference in food-restricted rats. Physiology \&Behavior, 73: $229-234$. Veterinary Science, 40: 219 - 224. GUYON, A., ASSOULY-BESSE, F., BIALA, G., PUECH, A. J. \& THIEBOT, M. H. (1993) Potentiation by low doses of selected neuroleptics of food-induced conditioned

702 place preference in rats. Psychopharmacology, 110: $460-466$. assessment for broiler breeder and layer females subjected to food restriction and limited access to water during rearing. British Poultry Science, 34: $443-458$. breeders.British Poultry Science, 37: 263 - 278. 
HOCKING, P. M., ZACZEK, V., JONES, E. K. M. \& MACLEOD, M. G. (2004)

710

Different concentrations and sources of dietary fibre may improve the welfare of female

711 broiler breeders. British Poultry Science, 45: 9 - 19.

HUGHES, R. A., BAKER, M. R. \& RETTIG, K. M. (1995) Cocaine-conditioned place

713 preference in young precocial domestic fowl.Experimental and Clinical

$714 \quad$ Psychopharmacology, 3: $105-111$.

715 IMAIZUMI, M., TAKEDA, M. \& FUSHIMI, T. (2000) Effects of oil intake in the

716 conditioned place preference test in mice. Brain Research, 870: 150 - 156.

717 IMAIZUMI, M., TAKEDA, M., SAWANO, S. \& FUSHIKI, T. (2001) Opoidergic

718 contribution to conditioned place preference induced by corn oil in mice. Behavioral

$719 \quad$ Brain Research, 121: $129-136$.

720 JAROSZ, P. A., SEKHON, P. \& COSCINA, D. V. (2006) Effect of opioid antagonism

721 on conditioned place preferences to snack foods.Pharmacology, Biochemistry and

722 behavior, 83: $257-264$.

723 JAROSZ, P. A., SEKHON, P. \& COSCINA, D. V. (2006) Effect of opioid antagonism

724 on conditioned place preferences to snack foods.Pharmacology, Biochemistry and

$725 \quad$ Behavior, 83: $257-264$.

726 KAPKOWSKA, E., GUMULKA, M. \& ROZENBOIM, I. (2005) An attempt at

727 improving welfare of broiler breeder hens during the rearing period by anorectic agents

728 and oat hulls in feed. Animal Science Paper and reports, 23(S1): 309 - 316.

729 KOIZUMI, M., CAGNIARD, B. \& MURPHY, N. P. (2009) Endogenous nociception

730 modulates diet preference independent of motivation and reward. Physiology

$731 \quad$ \&Behavior, 97: $1-13$. 
732 KIYATKIN, E. A. \& BELYI, V. P. (1991) Reinforcing properities of morphine used in

733 aversive life conditions: place preference paradigm, long-term changes in behavioural

734 reactivity. International Journal of Neuroscience, 57: 193 - 203.

735 LARSON, S. J. (2006) Lipopolysaccharide and interleukin-1 $\beta$ decrease sucrose intake

736 but do not affect expression of place preference in rats. Pharmacology, Biochemistry

737 and Behavior, 84: $429-435$.

738 LEPORE, M., VOREL, S. R., LOWINSON, J. \& GARDNER, E. L. (1995)

739 Conditioned place preference induced by $\Delta^{9}$-tetrahydrocannabinol: comparison with

$740 \quad$ cocaine, morphine and food reward. Life sciences, 56: $2073-2080$.

741 MACE, D. D., KRAEMER, P. J. \& AKINS, C. K. (1007) Conditioned place preference

742 in 12 day old japanese quail. Developmental Psychobiology, 31: 245 - 254.

743 MACFABE, D. F., CAIN, N. E., OSSENKOPP, K. P. \& CAIN, D. P. (2011) Effects of

744 the enteric bacterial metabolic product propionic acid on object-directed behaviour,

745 social behaviour, cognition, and neuroinflammation in adolescent rats: relevance to

746 autism spectrum disorder. Behavioural Brain Research, 217: 47 - 54.

747 MATSUMURA, S., YONEDA, T., AKI, S., EGUCHI, A., MANABE, Y., TSUZUKI,

748 S., INOUE, K. \& FUSHIKI, T. (2010) Intragastric infusion of glucose enhances the

749 rewarding effect of sorbitol fatty acid ester ingestion as measured by conditioned place

$750 \quad$ preference in mice. Physiology \&Behavior, 99: 509 - 514.

751 MUSCAT, R., PAPP, M. \& WILLNER, P. (1992) Reversal of stress-induced anhedonia

$752 \quad$ by the atypical antidepressants, fluoxetine and maprotiline.Psychopharmacology, 109:

$753 \quad 433-438$. 
PAPP, M. (1988) Different effects of short and long-term treatment with imipramine on the apo-morphine and food-induced place preference conditioning in rats.Pharmacology Biochemistry \&Behavior, 30: 889 - 893.

PAPP, M. (1989) Differential effects of short and long-term antidepressant treatments on the food-induced place preference conditioning in rats.Behavioural Pharmacology, 1: $69-74$.

PAPP, M., WILLNER, P. \& MUSCAT, R. (1991) An animal model of anhedonia:

PERKS, S. M. \& CLIFTON, P. G. (1996) Reinforcer revaluation and conditioned place

764 preference.Physiology \&Behavior, 61: $1-5$.

PETTENUZZO, L. F., SCHUCK, P. F., FONTELLA, F., WANNAMACHER, C. M., WYSE, A. T., SUTRA-FILHO, C. S., NETTO, C. A. \& WAJNER, M. (2002) Asorbic acid prevents cognitive deficits caused by chronic administration of propionic acid to attenuation of sucrose consumption and place preference conditioning by chronic unpredictable mild stress. Psychopharmacology, 104: 255 - 259.

\section{3} rats in the water maze. Pharmacology Biochemistry and Behavior, 73: 623 - 629.

PINCHASOV, Y. \& JENSEN, L. S. (1989) Effect of intubation of low-molecular POPIK, P. \& DANYSZ, W. (1997) Inhibition of reinforcing effects of morphine and motivational aspects of naloxone-precipitated opioid withdrawal by N-methy-D- 
777 aspartate receptor antagonist memantine.The Journal of Pharmacology and

$778 \quad$ Experimental Therapeutics, 280: $854-865$.

779 SANDILANDS, V., TOLKAMP, B. J. \& KYRIAZAKIS, I. (2005) Behaviour of food

780 restricted broilers during rearing and lay - effects of an alternative feeding

781 method.Physiology \&Behavior, 85: 115 - 123.

782 SANDILANDS, V., TOLKAMP, B.J., SAVORY, C. J. \& KYRIAZAKIS, I. (2006)

783 Behaviour and welfare of broiler breeders fed a qualitatively restricted diet: are there

784 viable alternatives to quantitative dietary restriction? Applied Animal Behaviour Science,

$78596: 53-67$.

786 SAVORY, C. J., MAROS, K. \& RUTTER, M. (1993) Assessment of hunger in growing

787 broiler breeders in relation to a commercial restricted feeding programme.Animal

$788 \quad$ Welfare, 2: $131-152$.

789 SAVORY, C. J. \& MAROS, K. (1993) Influence of degree of food restriction, age and 790 time of day on behaviour of broiler breeder chickens. Behavioural Processes, 29: 179 $791 \quad 190$.

792 SCHULTZ, S.R., MACFABE, D. F., MARTIN, S., JACKSON, J., TAYLOR, R.,

793 BOON, F., OSEENKOPP, K. P. \& CAIN, D. P. (2009) Intracerebroventricular

794 injections of the enteric bacterial metabolic product propionic acid impair cognition and

795 sensorimotor ability in the Long-Evans rat: further development of a rodent model of

796 autism. Behavioural Brain Research, 200: 33 - 41.

797 SPITERI, T., LE PAPE, G. \& AGMO, A. (2000) What is learned during place

798 preference conditioning? A comparison of food - and morphine-induced

$799 \quad$ reward.Psychobiology, 28: $367-382$. 
SPYRAKI, C., FIBIGER, H. C. \& PHILLIPS, A. G. (1982) Attentuation by Haloperidol of place preference conditioning using food reinforcement. Psychopharmacology, 77: $379-382$.

STUBER, G. D., EVANS, S. B., HIGGINS, M. S., PU, Y. \& FIGLEWICZ, D. P. (2002)

804 Food restriction modulates amphetamine-conditioned place preference and nucleus

805 accumbens dopamine release in the rat. Synapse, 46: $83-90$.

806 TOLKAMP, B. J., SANDILANDS, V\& KYRIAZAKIS, I. (2005)Effects of qualitative

807 feed restriction during rearing on on the performance of broiler breeders during

808 performance and lay. Poultry Science, 84: 1286 - 1293.

809 TZSCHENTKE, T.M. (1998) Measuring reward with the conditioned place preference 810 paradigm: a comprehensive review of drug effects, recent progress and new issues.

811 Progress in Neurobiology, 56: 613 - 672.

812 WIEPKEMA, P. R. \& KOOLHAAS, J. M. (1993) Stress and animal welfare.Animal $813 \quad$ Welfare, 2: $195-218$.

814 WILLNER, P., LAPPAS, S., CHEETA, S. \& MUSCAT, R. (1994) Reversal of stress815 induced anhedonia by the dopamine receptor agonist, pramipexole.

$816 \quad$ Psychopharmacology, 115: $454-462$.

817 YONGHUI, L., XIGENG, Z., YUNJING, B. \& NAN, S. (2006) Opposite effects of 818 MK-801 on the expression of food and morphine-induced conditioned place preference 819 in rats.Journal of Psychopharmacology, 20: 40 - 46. ZOMBECK, J. A., CHEN, G. T., JOHNSON, Z. V., ROSENBERG, D. M., CRAIG, A. B. \& RHODES, J. S. (2008) Neuroanatomical specificity of conditioned responses to cocaine versus food in mice. Physiology and behaviour, 93: $637-650$. 
Table 1: Study timeline showing key information relating to the experimental design

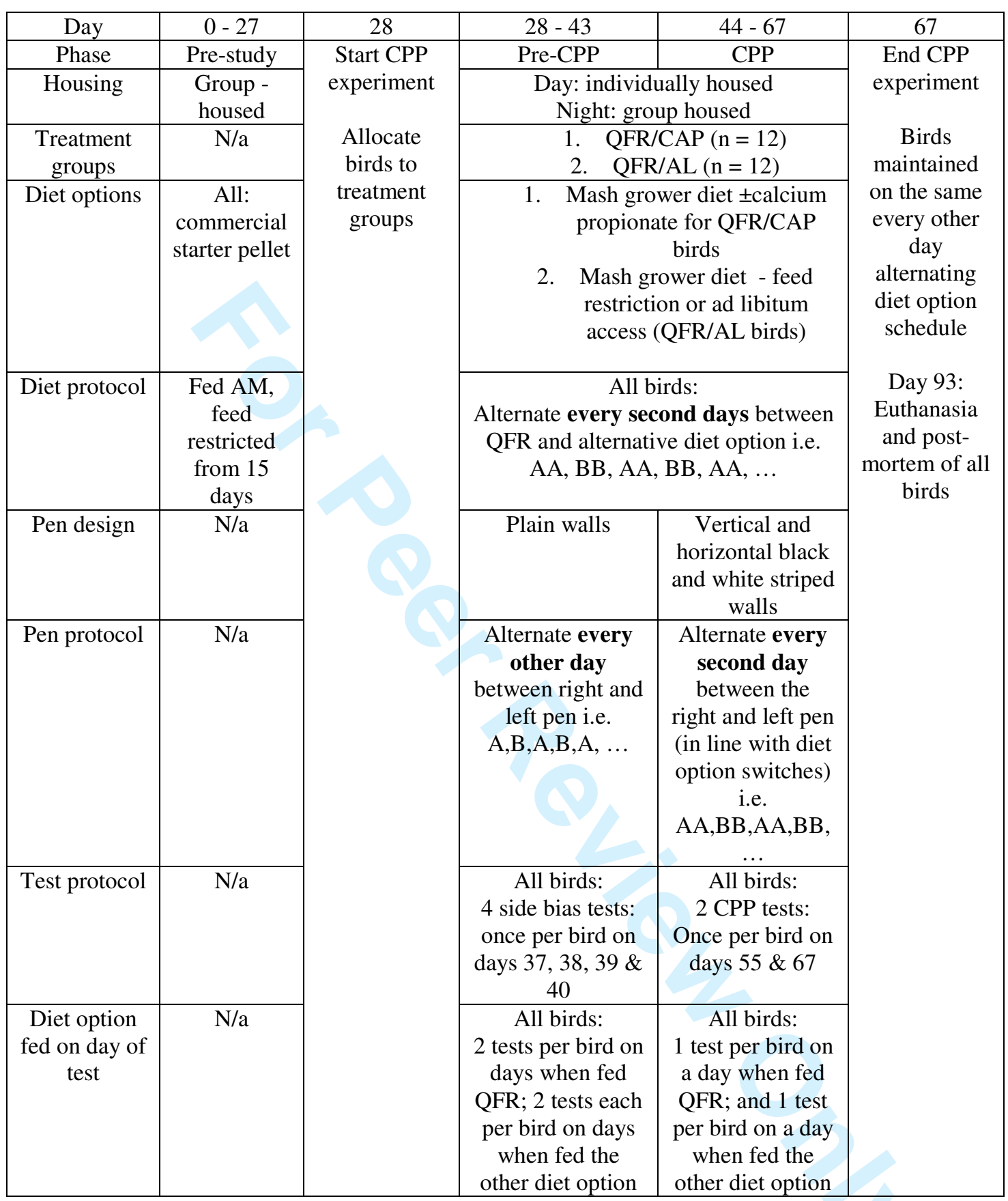


Figure 1: Diagram of CPP apparatus (not drawn to scale). The front of the pen (demarked by the two horizontal stand-alone lines) has been cut away to allow the reader to better visual the pen set-up during CPP testing.

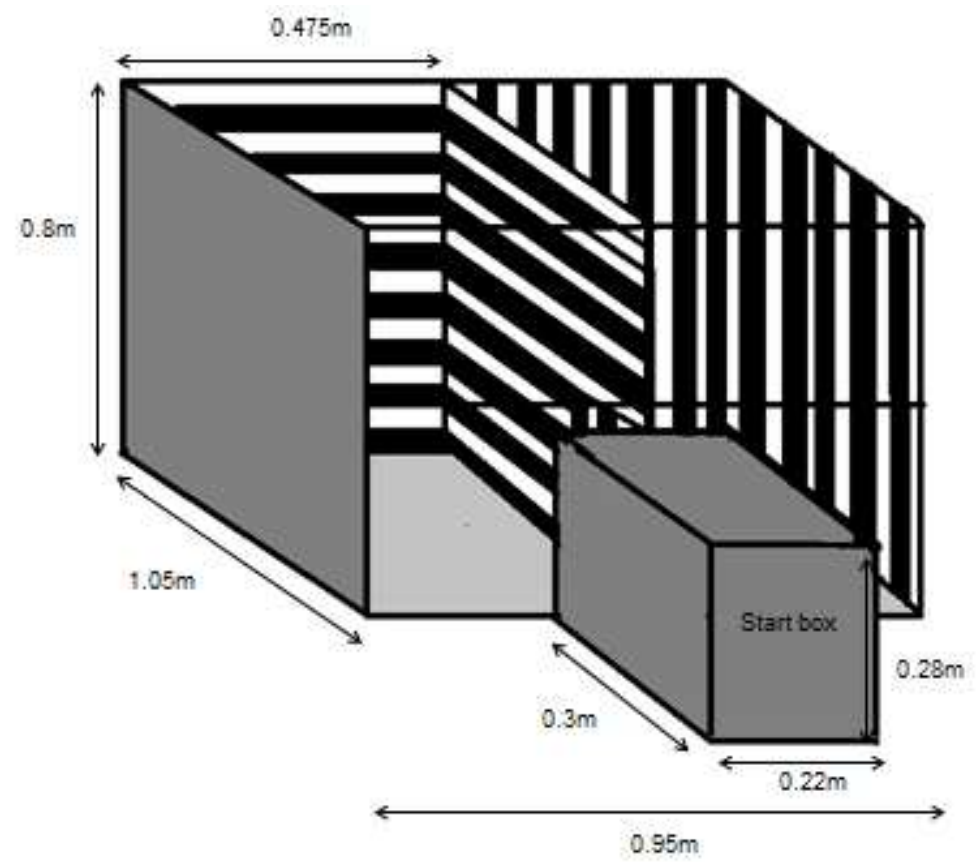


Figure 2: The growth rate of the birds in treatment groups QFR/AL and QFR/CAP. The target growth rate for Ross 308 Broiler Breeders (fed to $5 \%$ production at 25 weeks) is also shown for comparison. Error bars are omitted as the S.E.M. for each group was too small to illustrate effectively. The S.E.M. for each of the time points shown was as follows: QFR/AL: 9.1g; 12.2g; 23.5g; 26.2g; 37.2g; 32.5g; 43.0g; QFR/CAP: 9.9g; 6.7g; $6.7 \mathrm{~g} ; 7.9 \mathrm{~g} ; 9.0 \mathrm{~g} ; 7.9 \mathrm{~g} ; 9.0 \mathrm{~g}$. Bird growth rate is shown to 70 days (this trial ended on day 67 but the birds remained on the same diet protocol as they were re-used for a further experiment). 
Figure 3: Daily feed intake of the diet options by the treatment group QFR/AL and QFR/CAP. The error bars indicate the daily S.E.M. and are shown only for the AL group. The mean daily S.E.M. for QFR intake for both the QFR/AL and QFR/CAP treatment groups was 0g. The mean daily S.E.M. for CAP intake was $1 \mathrm{~g}$.

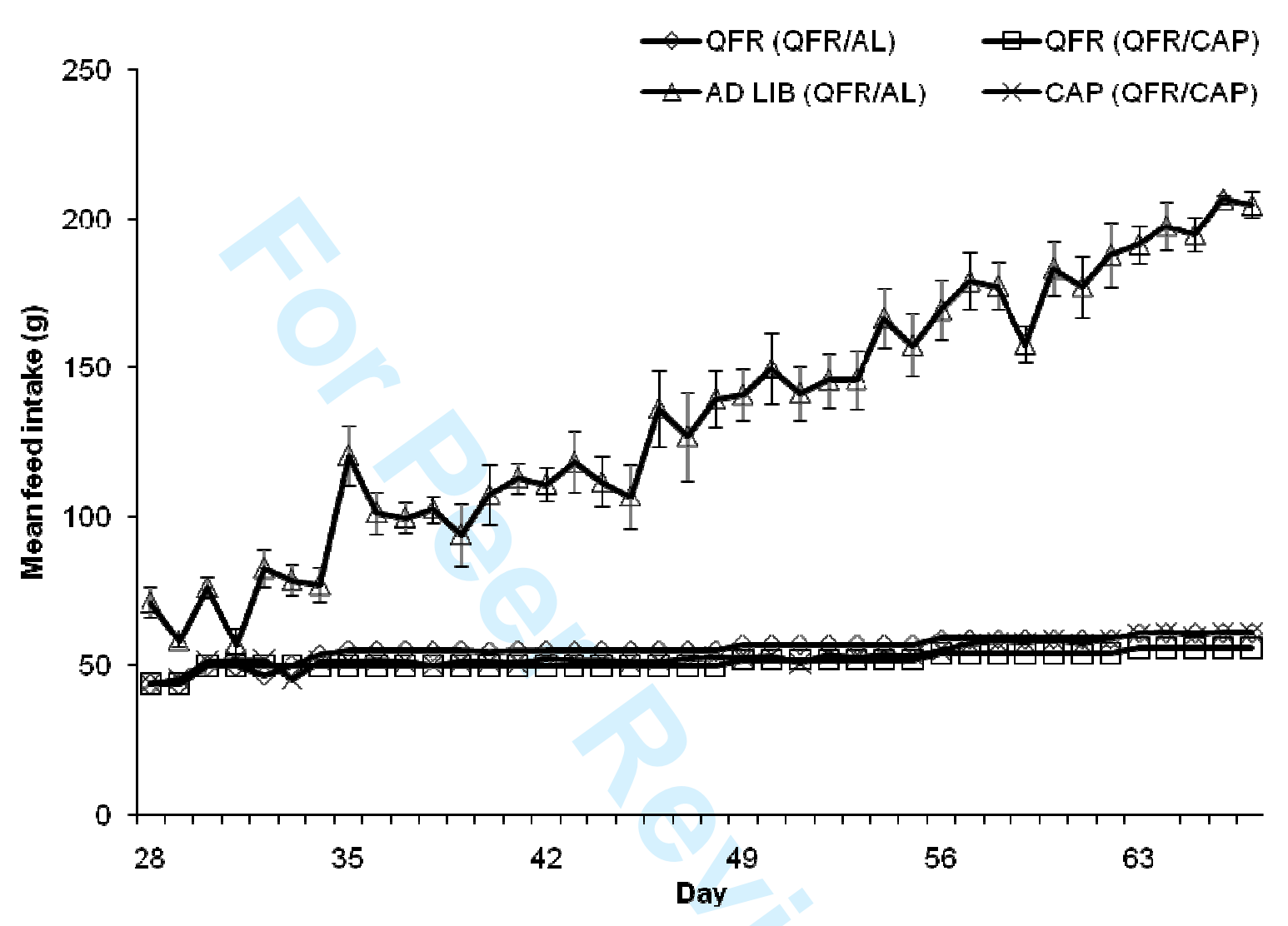


Figure 4: The time taken to consume either the CAP or the QFR ration by the treatment group QFR/CAP. The Inter-quartile ranges are shown by the error bars. The dashed horizontal line represents the $8 \mathrm{~h}$ cut off point. Birds failing to consume $\geq 95 \%$ of the daily ration by the $8 \mathrm{~h}$ cut off were awarded $9 \mathrm{~h}$ as a nominal value to aid graphical representation. There were no days on which birds failed to fully consume the QFR ration by $8 \mathrm{~h}$. The number of birds that failed to consume the full CAP ration by 8 h are as follows: day 28: 3; day 29: 5; day 30: 5; day 31: 5; day 32: 3; day 33; day 37: 1; day 38: 1; day 41: 2 ; day 45: 1 ; day 51: 3; on all other days 0 . The calcium propionate inclusion rate started at $3 \%$ and was increased to $4 \%$ on day $36(38), 5 \%$ on day $41(43), 6 \%$ on day 45 (47), $7 \%$ on day 49 (51), $8 \%$ on day 57 (59), 9\% on day 60 (62) and remained at $9 \%$ until the end of the study (day 67). Data was unavailable for CAP consumption on day 53.

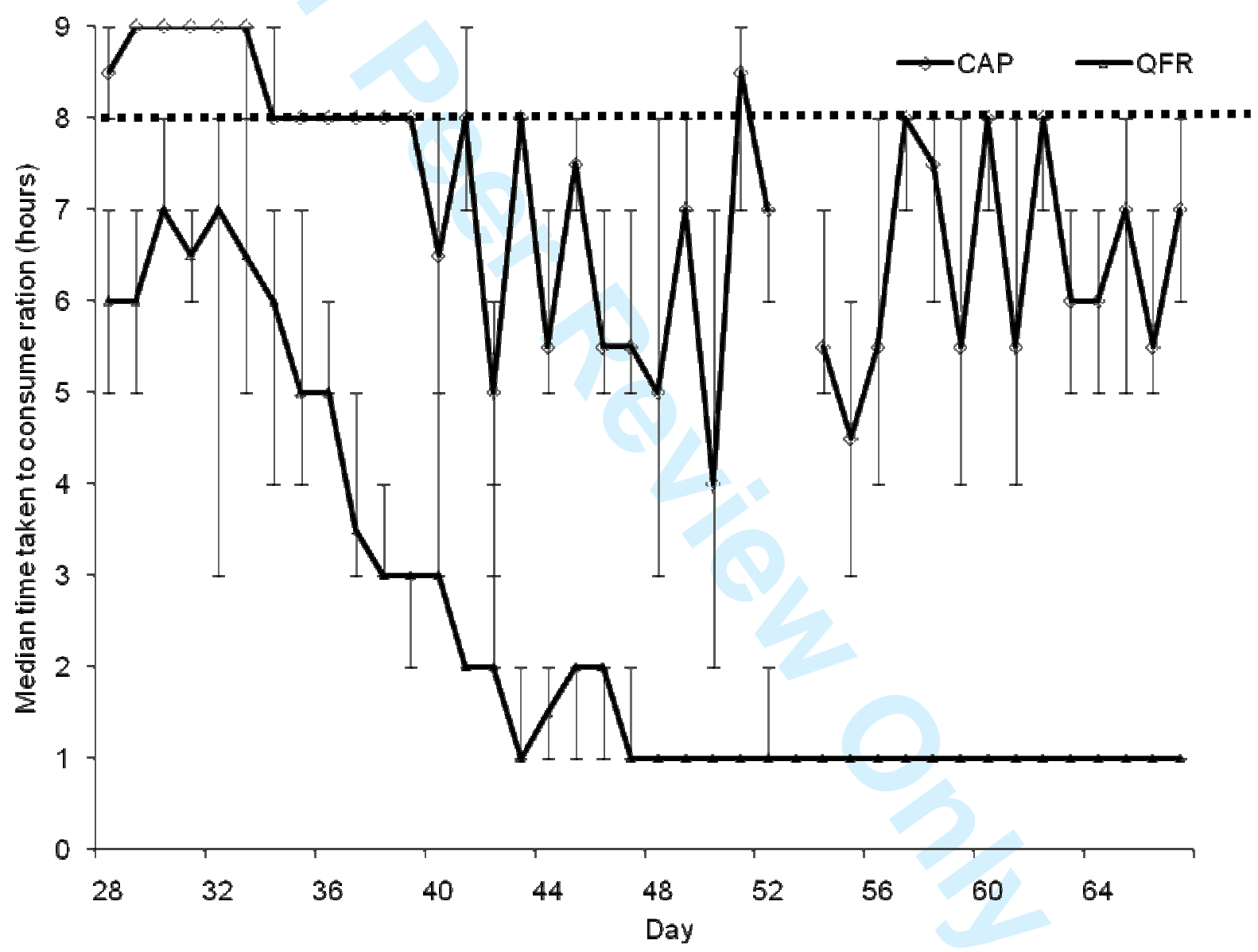


Figure 5: Effect of treatment and state at time of testing on proportion of time spent in the non-QFR associated pen. S.E.M. is indicated by the error bars. Only the QFR/AL treatment group, tested in a state of hunger (fed QFR on the day of testing) showed a significant preference $(\mathrm{P}<0.01$ level, denoted by **).

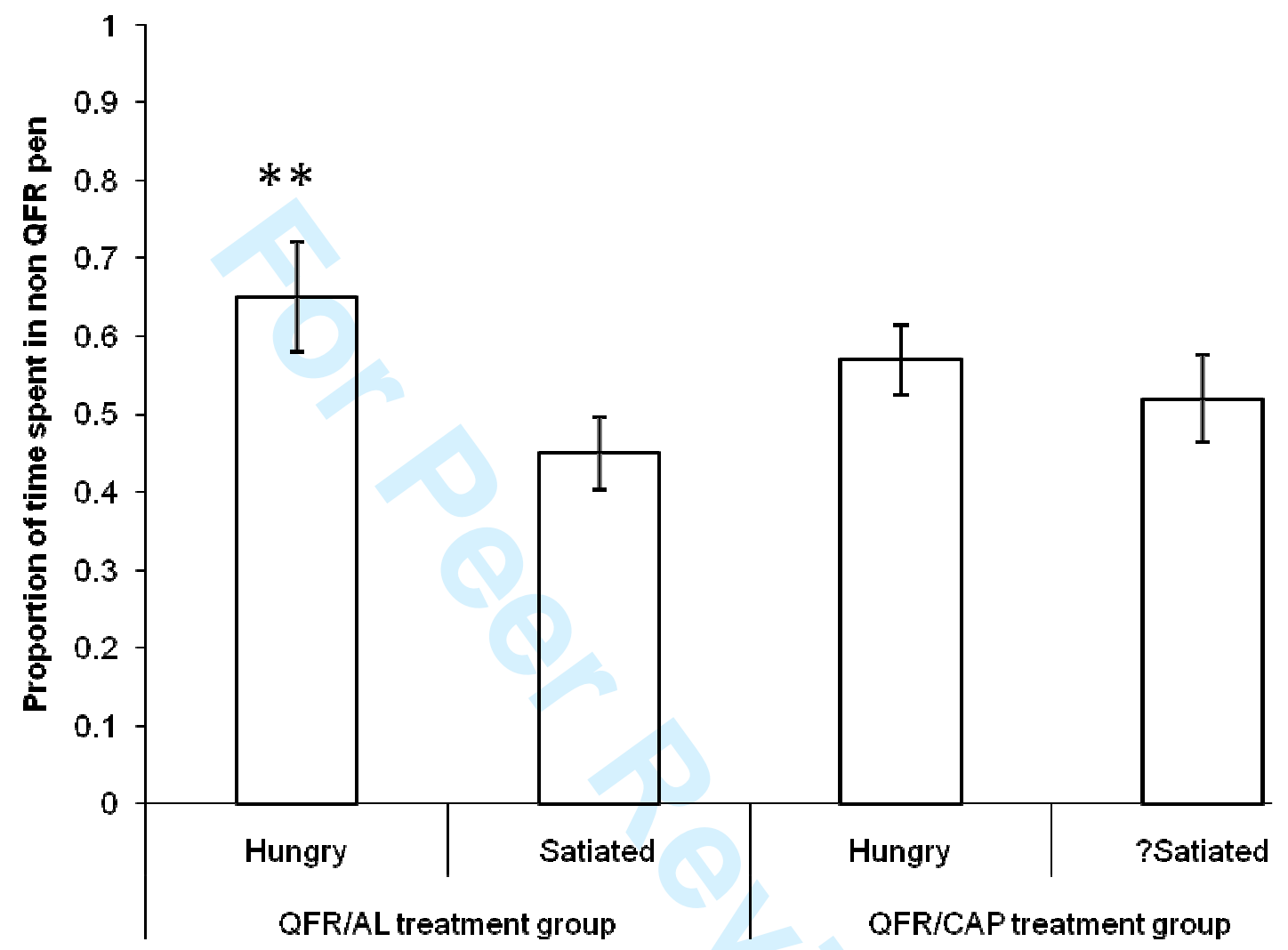

